\title{
Future Directions for Transuranic Single Molecule Magnets
}

\author{
Nicola Magnani and Roberto Caciuffo * \\ European Commission, Joint Research Centre (JRC), Directorate for Nuclear Safety and Security, P.O. Box 2340, \\ 76125 Karlsruhe, Germany; nicola.magnani@ec.europa.eu \\ * Correspondence: roberto.caciuffo@ec.europa.eu; Tel.: +49-7247-951-382
}

Received: 18 January 2018; Accepted: 8 February 2018; Published: 13 February 2018

\begin{abstract}
Single Molecule Magnets (SMMs) based on transition metals and rare earths have been the object of considerable attention for the past 25 years. These systems exhibit slow relaxation of the magnetization, arising from a sizeable anisotropy barrier, and magnetic hysteresis of purely molecular origin below a given blocking temperature. Despite initial predictions that SMMs based on 5f-block elements could outperform most others, the results obtained so far have not met expectations. Exploiting the versatile chemistry of actinides and their favorable intrinsic magnetic properties proved, indeed, to be more difficult than assumed. However, the large majority of studies reported so far have been dedicated to uranium molecules, thus leaving the largest part of the 5f-block practically unexplored. Here, we present a short review of the progress achieved up to now and discuss some options for a possible way forward.
\end{abstract}

Keywords: actinides; slow magnetic relaxation; single molecule magnets

\section{Introduction}

Mononuclear or multiple-spin centre complexes displaying large single-ion magnetic anisotropy and, for the latter, strong intramolecular exchange coupling have been intensively studied as potentially useful systems for quantum information processing, magnetic refrigeration, ultrahigh density memory components, or spintronic applications [1]. To be considered a single molecule magnet (SMM), a complex should display a large effective anisotropy barrier against magnetization reversal, $U_{\text {eff }}$, and a small relaxation rate, $\tau_{0}{ }^{-1}$, resulting in slow magnetic dynamics and in the opening of a hysteresis cycle below a blocking temperature $T_{\mathrm{B}}$. The aim of extensive research in the past 25 years has been to raise $T_{\mathrm{B}}$ and $U_{\text {eff }}$ as much as possible, ideally to synthesize systems with SMM behaviour above room temperature.

In order to improve the SMM figures of merit, initial studies focused on increasing the total spin of the molecule $S_{\text {tot }}$ using a large number of coupled magnetic centers. Synthetic efforts were therefore concentrated on $3 \mathrm{~d}$ block elements (mainly $\mathrm{Mn}, \mathrm{Fe}$ and $\mathrm{Cr}$ ), which afford strong magnetic exchange thanks to the large radial extension of their unfilled electronic shell [2-6]. This class of compounds suffers however from the small single-ion anisotropy typical of transition metals, whose angular momentum is quenched by the ligand field. Moving to the $4 \mathrm{f}$ block allowed one to partially overcome the impasse. Rare earths, with unquenched orbital degrees of freedom, exhibit a much larger single-ion anisotropy than transition metals, resulting in $U_{\text {eff }}$ values above $1800 \mathrm{~K}$ [7] and remanent magnetization up to about $60 \mathrm{~K}$ [8]. However, the exchange interaction between rare earths is usually smaller than in transition metals, so that the advantage offered by a coupled multi-centre structure is lost.

In the above scenario, actinides appeared as promising substitutes for the synthesis of high- $T_{\mathrm{B}}$ SMMs. Indeed, elements of the $5 \mathrm{f}$ block potentially combine single-ion anisotropy as large as in 
rare earths with exchange interactions strong enough to couple magnetic centres in polynuclear complexes. Moreover, contrary to rare earths, actinides can be stabilized in different oxidation states and are prone to form covalent bonds, thus offering an unparalleled chemical versatility in designing the molecular structure [9-11]. However, all actinide-based SMMs reported up to now perform significantly worse than the best rare-earth ones, in terms of both relaxation barrier and blocking temperature [12]. The slow progress in the field is in part due to the relative smallness of the actinide scientific community, and to the fact that only a handful of laboratories are equipped to handle transuranic elements, so that most of the reported work concerns uranium complexes only. SMM behaviour has actually been observed in several monometallic $\mathrm{U}^{\mathrm{III}}$ [13] and $\mathrm{U}^{\mathrm{V}}$ [14] complexes and in heterometallic coordination compounds containing $\mathrm{U}^{\mathrm{V}}$ and either $\mathrm{Mn}^{\mathrm{II}}$ or Dy ${ }^{\mathrm{III}}$ cations [15-17]. The results obtained on these systems have been the subject of recent reviews [12,18-20]. Here, we will critically summarize the attempts to obtain SMMs based on transuranic elements, mainly Np and $\mathrm{Pu}$, focusing on the reasons for the limited success obtained so far and trying to indicate a possible direction for future research.

\section{A Survey of the Existing Transuranic Single Molecule Magnets}

In this article, following a convention used in a large part of the literature, we extend the definition of SMMs to include molecular complexes for which clear evidence of a low temperature slowing down of the magnetization dynamics exists, even though their blocking temperature has not been experimentally determined.

The three SMMs based on transuranic elements which have been reported in the literature so far are pictured in Figure 1: heterovalent trimetallic neptunyl complex $\left\{\left(\mathrm{Np}^{\mathrm{VI}} \mathrm{O}_{2}\right) \mathrm{Cl}_{2}\right\}\left\{\left(\mathrm{Np}^{\mathrm{V}} \mathrm{O}_{2}\right) \mathrm{Cl}(\text { thf })_{3}\right\}_{2}$ (thf = tetrahydrofuran), hereafter referred to as $\mathrm{Np}_{3}$ (a) [21]; the $\mathrm{Np}^{\mathrm{IV}}$-based sandwich complex $\mathrm{Np}(\mathrm{COT})_{2}\left(\mathrm{COT}=\right.$ cyclooctatetraenide), commonly known as neptunocene (b) [22]; and the $\mathrm{Pu}^{\mathrm{III}}$ monometallic $\mathrm{PuTp}_{3}$ (Tp = trispyrazolylborate) (c) [23].

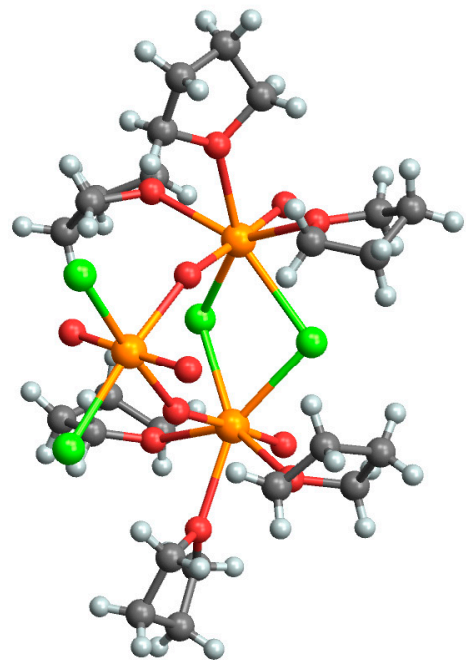

(a)

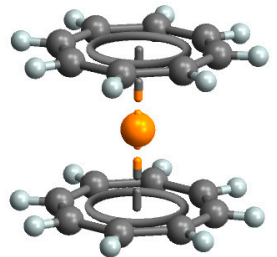

(b)

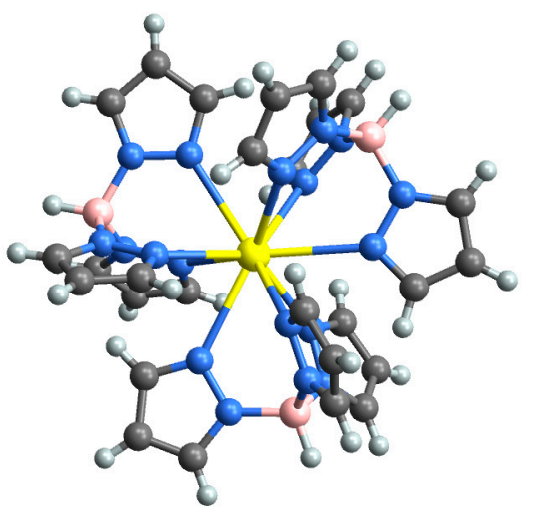

(c)

Figure 1. Ball-and-stick structural representation of the three transuranic SMMs reported in the literature so far: (a) $\mathrm{Np}_{3}$; (b) $\mathrm{Np}(\mathrm{COT})_{2}$; and (c) $\mathrm{PuTp}_{3}$. The color scheme used for labeling atoms is the following: light gray $=\mathrm{H}$, pink $=\mathrm{B}$, dark gray $=\mathrm{C}$, blue $=\mathrm{N}$, red $=\mathrm{O}$, green $=\mathrm{Cl}$, orange $=\mathrm{Np}$, yellow $=\mathrm{Pu}$.

\section{1. $\mathrm{Np}_{3}$}

$\mathrm{Np}_{3}$ was the first studied example of a polymetallic transuranium complex displaying both slow relaxation of the magnetization and effective superexchange interactions between the actinide centers. 
Two of the three $\mathrm{Np}$ ions are pentavalent, with $\mathrm{O}$ and $\mathrm{Cl}$ ligands arranged around them in a distorted pentagonal bipyramidal arrangement; in turn, one neptunyl oxygen from each $\mathrm{Np}^{\mathrm{V}}$ coordinates into the equatorial plane of the hexavalent $\mathrm{Np}$ center, whose distorted tetragonal bipyramidal ligand geometry is completed by two $\mathrm{Cl}$ anions [24]. Measurements of the dc magnetic susceptibility $\chi$ as a function of temperature $T$, shown in Figure $2 \mathrm{a}$, display a clear upturn in the $\chi T$ vs. $T$ curve upon cooling below $30 \mathrm{~K}$, which is a typical feature of ferromagnetically-coupled systems. In truth, calculations have shown that the leading exchange interaction within the complex is the one between the $\mathrm{Np}^{\mathrm{VI}}$ and each of the $\mathrm{Np}^{\mathrm{V}}$ centers and is antiferromagnetic; however, the magnetic moment carried by the former ion is smaller than those on the latter, which turn out to be parallel as if there were an effective ferromagnetic interaction between them. The magnetization dynamics of the system have been studied by ac susceptibility measurements, and fitting the experimentally deduced $T$-dependence of the relaxation time $\tau$ shown in Figure $2 \mathrm{~b}$ leads to an energy barrier $U_{\text {eff }}=140 \mathrm{~K}$, surprisingly high given that the expected exchange gap for the system is around $25 \mathrm{~K}$. The reason for this discrepancy might be that the steepness of the curve makes the accessible temperature range relatively narrow, so that the actual relaxation process is more complicated than a simple Orbach model [20]. This would also explain why the prefactor $\tau_{0}$ seems significantly smaller compared to other systems.

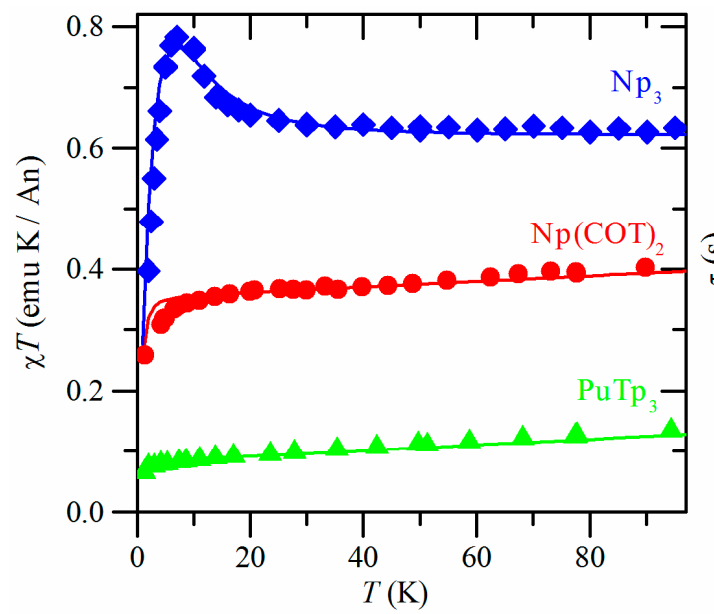

(a)

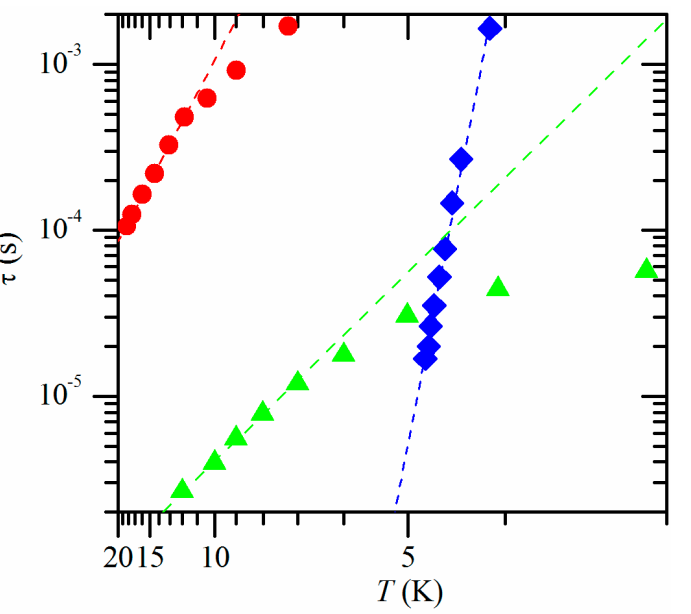

(b)

Figure 2. (a) Temperature ( $T$ ) dependence of the dc magnetic susceptibility per actinide ion $(\chi)$, plotted as $\chi T$ vs. $T$ curves. Points are experimental data (blue diamonds: $\mathrm{Np}_{3}$, red circles: $\mathrm{Np}(\mathrm{COT})_{2}$, green triangles: $\mathrm{PuTp}_{3}$ ), lines are calculations (see main text for details); (b) Arrhenius (log-reciprocal) plot of the relaxation time $\tau$ as a function of $T$. Points (same legend as for the other panel) are experimental data derived from ac susceptibility measurements, dashed lines are fits of the high-temperature points to an Orbach law $\tau=\tau_{0} \exp \left(U_{\text {eff }} / k T\right)$. All data, fits and calculations are from references [21-23].

\section{2. $\mathrm{Np}(\mathrm{COT})_{2}$}

Actinocenes (monometallic complexes where a tetravalent actinide cation is sandwiched between two aromatic cyclooctatetraenide anions) were synthesized with $\mathrm{U}, \mathrm{Np}$ and $\mathrm{Pu}$ at the end of the Sixties $[25,26]$. In contrast with earlier assumptions, the actinide-cyclooctatetraenyl bonding was recently shown to be mainly due to $6 \mathrm{~d}$ orbitals mixing into the ligand $\pi$-orbitals, so that the $5 \mathrm{f}$ electrons are not significantly involved [27]. The measured $\chi T$ vs. $T$ curve is essentially linear down to about $10 \mathrm{~K}$, and decreases sharply at lower temperatures due to saturation effects. The effective magnetic moment is very close to that of a pure $J_{z}= \pm 5 / 2$ doublet. Indeed, the degeneracy of the lowest $J=9 / 2$ manifold belonging to the $5 \mathrm{f}^{3}$ configuration is partially removed by the axial ligand-field potential, which isolates a $J_{z}= \pm 5 / 2$ doublet as the ground state. A detailed analysis combining ligand field and quantum chemistry calculations, reported in [22], shows that the first excited energy levels have 
a $J_{z}= \pm 3 / 2$ or $J_{z}= \pm 7 / 2$ character and are not lower than $1400 \mathrm{~cm}^{-1}$ in energy with respect to the ground state.

The highly axial $\mathrm{D}_{8 \mathrm{~h}}$ symmetry of the actinocene family and the fact that $\mathrm{Np}^{\mathrm{IV}}$ is a Kramers' ion make neptunocene a very promising SMM and indeed, in order to explain anomalies observed in Np-Mössbauer spectra, the occurrence of slow magnetic relaxation was postulated [26] two decades before the term "single molecule magnet" was even coined. This was verified in more recent years by measurements of the ac magnetic susceptibility, whose out-of-phase component displays a frequency-dependent peak in the temperature range $2-60 \mathrm{~K}$ when a static external magnetic field larger than $0.1 \mathrm{~T}$ is applied [22]. The temperature dependence of the relaxation time $\tau$, measured with an applied static magnetic field B of $0.5 \mathrm{~T}$, is shown as an Arrhenius plot in Figure $2 \mathrm{~b}$. The approximately linear behavior is broken at low temperatures, where a significant deviation reminiscent of quantum tunneling of the magnetization (QTM) is observed. An increase of the static field amplitude suppresses QTM. For $B=3 T$, the $\ln \tau$ versus $1 / T$ plot is essentially linear in the whole range of measured temperatures and corresponds to $U_{\text {eff }}=41 \mathrm{~K}$ and $\tau_{0}=1.1 \times 10^{-5} \mathrm{~s}$. At larger fields the magnetization dynamics at low temperatures slow down considerably and magnetic bistability appears. This results in a "butterfly-shaped" hysteresis cycle at $1.8 \mathrm{~K}$, where a difference between the field-up and field-down curves exists only above $5 \mathrm{~T}$ but no remanence is present. This behavior is believed to be caused by the hyperfine interaction between the double-degenerate electronic ground state and the $I=5 / 2$ nuclear spin of ${ }^{237} \mathrm{~Np}$, which at low magnetic field values creates crossing points between states with opposite $J_{z}$ where the fast, direct relaxation processes are enhanced.

\section{3. $\mathrm{PuTp} 3$}

The third (and so far the last) reported transuranic SMM, PuTp 3 , is also the first one based on plutonium rather than neptunium. The $\mathrm{Pu}{ }^{\mathrm{III}}$ cation is nine-coordinated to the $\mathrm{N}$ atoms of the three $\mathrm{Tp}$ ligands around it in a tricapped trigonal prismatic geometry, in a crystallographically exact $\mathrm{D}_{3 \mathrm{~h}}$ point group symmetry. Its uranium analog, $\mathrm{UTp}_{3}$, is also a SMM [28]; this complex is not interesting for its low effective barrier $\left(U_{\text {eff }}=5.5 \mathrm{~K}\right)$, but rather for the availability of detailed optical spectra, from which all the symmetry-allowed ligand-field parameters could be derived [29]. In turn, these were used to model the measured dc magnetic susceptibility for $\mathrm{PuTp}_{3}$; as shown in Figure 2a the calculated curve matches the experimental values well.

Interestingly, the only non-axial ligand-field parameter is of rank 6, so it affects the $J=9 / 2$ manifold of $\mathrm{U}^{\mathrm{III}}$ but not the $J=5 / 2$ manifold of $\mathrm{Pu}^{\mathrm{III}}$; as a result, the ground state of $\mathrm{PuTp}_{3}$ is an almost pure $J_{z}= \pm 5 / 2$ doublet (the first excited state, the $J_{z}= \pm 3 / 2$ doublet, is separated by a gap of $477 \mathrm{~K})$. Its charge-density distribution has therefore an oblate character: this makes it more prone to SMM behaviour than the prolate $\mathrm{UTp}_{3}$ in an axial "sandwich-type" environment [30]. The $\tau$ vs. $T$ curve of $\mathrm{PuTp}_{3}$ derived from ac susceptibility measurement with a static field of 100 Oe is shown in Figure $2 \mathrm{~b}$; its high-temperature part was fitted assuming that a single Orbach process is active, giving the figures of merit $U_{\text {eff }}=26.3 \mathrm{~K}$ and $\tau_{0}=2.9 \times 10^{-7} \mathrm{~s}$. However, removing the static field altogether, the ac out-of-phase signal becomes very weak; furthermore, no magnetic hysteresis was observed in the magnetization curves down to $1.8 \mathrm{~K}$ [23].

\section{A Difficult Path Forward}

\subsection{Monometallic Complexes}

Lessons learned from lanthanide SMM research point towards two main ingredients to build good single-ion magnets: (1) a pure, doubly degenerate Ising ground state to eliminate direct relaxation processes as much as possible and (2) a large energy gap with the first excited level to make thermally activated processes slow enough. Theoretically speaking, condition (1) can be met reasonably well only for $\mathrm{Ho}^{3+}$, $\mathrm{Dy}^{3+}$, and $\mathrm{Er}^{3+}$ [31], with the latter two being favoured by their Kramers nature (so that the degeneracy of a doublet ground state cannot be further reduced without breaking time reversal 
too), but in practice SMMs with most other lanthanides have been realized as well [1]. In any case, the axial character of the ground state must be enhanced, by a high local symmetry or by other means such as the preponderant covalent binding to a single ligand atom [32].

Slow magnetic relaxation has been observed in monometallic complexes of the Kramers ion UIII with low symmetry (or even none at all!) [33]. Therefore, neptunocene should have been a breakthrough according to the above rules. Indeed, the $\mathrm{Np}^{\mathrm{IV}}$ cation in this molecule is isoconfigurational with $\mathrm{U}^{\mathrm{III}}$, is strongly bonded between two aromatic cycles, and displays an almost axial symmetry. As discussed in Section 2, the reason behind its relatively disappointing performance is the hyperfine interaction which, upon application of a magnetic field, creates "diabolic" crossing points where fast direct relaxation processes are enhanced [22]. Unfortunately, the drawback associated with the presence of a nuclear spin cannot be overcome by simply choosing another neptunium isotope, since ${ }^{237} \mathrm{~Np}$ is the only one with half-life long enough to be practically useful. For this reason, even if several high-symmetry, potentially interesting $\mathrm{Np}^{\mathrm{IV}}$-based monometallic clusters have been synthesized and reported in the literature [34,35], the unavoidable presence of hyperfine interaction is expected to strongly limit their performances as SMM. The effect on the non-Kramers $\mathrm{Np}^{\mathrm{III}}$ ion could be even worse. For instance, reductive oxo-metalation of uranyl complexes by $\mathrm{UCp}_{3}$ affords a $\mathrm{U}^{\mathrm{IV}}-\mathrm{U}^{\mathrm{V}}$ hetero-valent dimer that behaves as a SMM below $4 \mathrm{~K}$; on the other hand, the same reaction by $\mathrm{NpCp}_{3}$ gives an isostructural donor-acceptor oxo bridged $\mathrm{Np}^{\mathrm{III}}-\mathrm{U}^{\mathrm{VI}}$ dimer with magnetic properties closely matching those of an isolated $\mathrm{Np}^{\mathrm{III}}$ ion but no slow relaxation [36]. Similarly disappointing results have been reported for a $\mathrm{Np}^{\mathrm{III}}$ organometallic compound with a bis(arene)-type geometry that exhibits slow relaxation of the magnetization only well below $2 \mathrm{~K}$, despite a favourable ligand arrangement [37].

Concerning plutonium, long-lived isotopes with zero nuclear spin are available so hyperfine interaction can be avoided, and the fact that its most common cation, $\mathrm{Pu}^{\mathrm{III}}$, is a Kramers ion makes it potentially interesting. Furthermore, as it was shown in the case of $\mathrm{PuTp}_{3}$, in hexagonal point symmetry the effect of non-axial ligand-field terms within the ground manifold disappears. Possible drawbacks of plutonium-based SMM are the lower magnetic moment with respect to $\mathrm{U}^{\mathrm{III}}$ and the fact that in the case of $\mathrm{Pu}^{\mathrm{IV}}$ the ground state is generally non-magnetic.

\subsection{Polymetallic Complexes}

The detrimental effects of hyperfine interaction on slow magnetic relaxation can be overcome by switching on an exchange coupling between magnetic centres, strong enough to eliminate level crossings. This is the case of $\mathrm{Np}_{3}$, where an exchange gap of $25 \mathrm{~K}$ is sufficient to ensure that the slow magnetic relaxation is not disrupted. This suggests that efforts to synthesise neptunium-based SMM should concentrate on polynuclear complexes rather than single-ion molecules. An example of promising complex is the tetrameric cation-cation neptunyl(V) cluster $\mathrm{Np}_{4}$ reported in [38] ([\{ $\mathrm{NpO}_{2}$ (salen) $\left.\}_{4}\left(\mu_{8}-\mathrm{K}\right)_{2}\right][\mathrm{K}(18 \mathrm{C} 6) \mathrm{Py}]_{2}$, with $\mathrm{H}_{2}$ salen = N, $\mathrm{N}^{\prime}$-ethylene-bis(salicylideneimine), Py $=$ pyridine, $18 \mathrm{C} 6=1,4,7,10,13,16$-hexaoxacyclooctadecane). A strong antiferromagnetic coupling has been reported for a binuclear $\mathrm{U}^{\mathrm{V}}$ complex with similar oxygen coordination [11]. It is likely that antiferromagnetic coupling is also active in $\mathrm{Np}_{4}$; taking into account the strong axial anisotropy of the actinyl group, this would lead to a ground state with anapole-like arrangement of the spins but zero total magnetic moment, as for the $\mathrm{U}_{3}$ complex discussed in [39]. On the other hand, it has been suggested that the reaction of a pentavalent uranium tetramer analogue to $\mathrm{Np}_{4}$ with hexavalent uranyl can lead to oxo-group functionalization and to the formation of a heterovalent $3 \mathrm{U}^{\mathrm{V}}-1 \mathrm{U}^{\mathrm{VI}}$ complex [40]. If this could be achieved for $\mathrm{Np}_{4}$, the imbalance could result in a molecule with non-zero magnetic moment, with potential SMM behaviour.

In the case of plutonium, only a handful of high symmetry polymetallic clusters have been reported. One notable example is the $\mathrm{Pu}{ }^{\mathrm{VI}}$ dimer $\left[\mathrm{PuO}_{2} \mathrm{Cl}_{2}\left(\mathrm{thf}_{2}\right]_{2}\right.$, prepared by addition of a $\mathrm{HCl} / \mathrm{Et}_{2} \mathrm{O}$ solution to a suspension of $\mathrm{PuO}_{2} \mathrm{CO}_{3}$ in thf [41]. The $5 \mathrm{f}^{2}$ electronic configuration of $\mathrm{Pu}^{\mathrm{VI}}$ in the strongly axial plutonyl geometry is expected to give rise to a magnetic ground state. The two $\mathrm{Cl}$ bridges connecting the metal centres provide a pathway for exchange interaction, although it could be 
antiferromagnetic as in $\mathrm{Np}_{3}$ where similar $\mathrm{Np}^{\mathrm{V}}-\mathrm{Cl}$ bonds exist. Were the $\mathrm{Pu}{ }^{\mathrm{VI}}-\mathrm{Pu}{ }^{\mathrm{VI}}$ coupling small, a metastable magnetic ground state could be induced by the application of an external magnetic field.

Surprises could come from actinide clusters with very high spin ground state $S_{\text {tot }}$. Recent computational studies [42] have suggested that self-assembled, multi-shell, onion-like geometry An-M $\left(\mathrm{An}=\mathrm{Np}, \mathrm{Pu} ; \mathrm{M}=\right.$ transition metal) complexes, analogue to the fullerene-like $\mathrm{Na}_{12} @ \mathrm{U}_{20}$ cluster [43], could exhibit a record-high $\mathrm{S}_{\text {tot }}$ value. In the case of a hypothetical icosahedral three-shell cluster based on $\mathrm{Mn}^{2+}$ and plutonyl ${ }^{\mathrm{VI}}\left(\mathrm{PuO}_{2}{ }^{2+}\right)$, with a sulphur dianion at the centre of the cluster, the predicted $S_{\text {tot }}$ value is $100 / 2$. If confirmed, this would be the largest ground state spin value ever observed for a molecular cluster and could be associated with a large anisotropy barrier against magnetization reversal.

\section{Conclusions}

The use of actinide metal centres to obtain SMMs with blocking temperature high enough for practical applications was undertaken because of their potentially favorable electronic properties. A spin-orbit coupling larger than in the 4f-block could improve single-ion anisotropy and the propensity for covalent bonding could promote magnetic exchange coupling in polymetallic complexes. Moreover, the higher versatility offered by actinide chemistry in comparison with that of trivalent lanthanides should aid attempts to engineer the ligand geometry. However, expectations have been so far frustrated because the interplay between fundamental electronic interactions, active degrees of freedom, and local symmetry in actinide complexes proved to be much more cumbersome than originally assumed. In the case of $3 \mathrm{~d}$ and $4 \mathrm{f}$ elements, strategies for the optimization of the ligand field design have emerged from the massive amount of data made available by two decades of extensive studies carried out by a large number of multidisciplinary research groups, and in more than one occasion also thanks to serendipity. This cannot be expected for transuranium elements, which can be handled only in very few licensed laboratories; a leading role of theoretical modelling is therefore required to steer experimental work towards success.

Models based on effective Hamiltonians acting on a reduced Hilbert space have been very successful in describing the properties of both transition metal and lanthanide complexes. Similar approaches applied to uranium SMMs [44], although able to rationalize the observed magnetic properties, have limited predictive capabilities. In fact, the complexity of the fundamental interactions requires the use of a full Hamiltonian acting on the whole electronic configuration and correctly including intra-atomic Coulomb interactions, relativistic effects, and the crystal field potential [45]. The number of independent parameters in this approach is far too large to be determined from magnetic measurements alone and call for extensive spectroscopic studies. Interesting developments are promised by multiconfigurational electronic structure theory calculations including spin-orbit coupling. Such first principles techniques have recently been applied to study trends in magnetic properties of uranium-based SMMs with encouraging results [46]. Although the treatment of heavier atoms increases the computational cost, this approach can easily be extended to transuranics and can provide valuable indications about the most favourable coordination topologies.

Despite what could be perceived as limited success, research in this field has already led to some interesting discoveries. As many potential pathways remain untrodden, we believe that breakthroughs are within reach, provided that the necessary resources are deployed, both in theory and experiments.

Author Contributions: The manuscript was written by Nicola Magnani and Roberto Caciuffo.

Conflicts of Interest: The authors declare no conflict of interest.

\section{References}

1. Gao, S. Molecular Nanomagnets and Related Phenomena; Springer: Berlin, Germany, 2015; ISBN 978-3-662-45722-1.

2. Sessoli, R.; Gatteschi, D.; Caneschi, A.; Novak, M.A. Magnetic bistability in a metal-ion cluster. Nature 1993, 365, 141-143. [CrossRef] 
3. Sangregorio, C.; Ohm, T.; Paulsen, C.; Sessoli, R.; Gatteschi, D. Quantum Tunneling of the Magnetization in an Iron Cluster Nanomagnet. Phys. Rev. Lett. 1997, 78, 4645-4648. [CrossRef]

4. Van Slageren, J.; Sessoli, R.; Gatteschi, D.; Smith, A.A.; Helliwell, M.; Winpenny, R.E.P.; Cornia, A.; Barra, A.-L.; Jansen, A.G.M.; Rentschler, E.; et al. Magnetic Anisotropy of the Antiferromagnetic Ring [Cr ${ }_{8} \mathrm{~F}_{8} \mathrm{Piv}_{16}$ ]. Chem. Eur. J. 2002, 8, 277-285. [CrossRef]

5. Santini, P.; Carretta, S.; Amoretti, G.; Guidi, T.; Caciuffo, R.; Caneschi, A.; Rovai, D.; Qiu, Y.; Copley, J.R.D. Spin dynamics and tunneling of the Néel vector in the $\mathrm{Fe}_{10}$ magnetic wheel. Phys. Rev. B 2005, 71, 184405. [CrossRef]

6. Waldmann, O.; Carretta, S.; Santini, P.; Koch, R.; Jansen, A.G.M.; Amoretti, G.; Caciuffo, R.; Zhao, L.; Thompson, L.K. Quantum Magneto-Oscillations in a Supramolecular Mn(II)-[3 × 3] Grid. Phys. Rev. Lett. 2004, 92, 096403. [CrossRef] [PubMed]

7. Ding, Y.-S.; Chilton, N.F.; Winpenny, R.E.P.; Zheng, Y.-Z. On Approaching the Limit of Molecular Magnetic Anisotropy: A Near-Perfect Pentagonal Bipyramidal Dysprosium(III) Single-Molecule Magnet. Angew. Chem. Int. Ed. 2016, 55, 16071-16074. [CrossRef] [PubMed]

8. Goodwin, C.A.P.; Ortu, F.; Reta, D.; Chilton, N.F.; Mills, D.P. Molecular magnetic hysteresis at 60 kelvin in dysprosocenium. Nature 2017, 548, 439-442. [CrossRef] [PubMed]

9. Arnold, P.L.; Dutkiewicz, M.S.; Walter, O. Organometallic Neptunium Chemistry. Chem. Rev. 2017, 117, 11460-11475. [CrossRef] [PubMed]

10. Nocton, G.; Horeglad, P.; Pécaut, J.; Mazzanti, M. Polynuclear Cation-Cation Complexes of Pentavalent Uranyl: Relating Stability and Magnetic Properties to Structure. J. Am. Chem. Soc. 2008, 130, 16633-16645. [CrossRef] [PubMed]

11. Arnold, P.L.; Jones, G.M.; Odoh, S.O.; Schreckenbach, G.; Magnani, N.; Love, J.B. Strongly coupled binuclear uranium-oxo complexes from uranyl oxo rearrangement and reductive silylation. Nat. Chem. 2012, 4, 221-227. [CrossRef] [PubMed]

12. McAdams, S.G.; Ariciu, A.-M.; Kostopoulos, A.K.; Walsh, J.P.S.; Tuna, F. Molecular single-ion magnets based on lanthanides and actinides: Design considerations and new advances in the context of quantum technologies. Coord. Chem. Rev. 2017, 346, 216-239. [CrossRef]

13. Rinehart, J.D.; Long, J.R. Slow Magnetic Relaxation in a Trigonal Prismatic Uranium(III) Complex. J. Am. Chem. Soc. 2009, 131, 12558-12559. [CrossRef] [PubMed]

14. King, D.M.; Tuna, F.; McMaster, J.; Lewis, W.; Blake, A.J.; McInnes, E.J.L.; Liddle, S.T. Single-Molecule Magnetism in a Single-Ion Triamidoamine Uranium(V) Terminal Mono-Oxo Complex. Angew. Chem. Int. Ed. 2013, 52, 4921-4924. [CrossRef] [PubMed]

15. Mougel, V.; Chatelain, L.; Pécaut, J.; Caciuffo, R.; Colineau, E.; Griveau, J.-C.; Mazzanti, M. Uranium and manganese assembled in a wheel-shaped nanoscale single-molecule magnet with high spin-reversal barrier. Nat. Chem. 2012, 4, 1011-1017. [CrossRef] [PubMed]

16. Mougel, V.; Chatelain, L.; Hermle, J.; Caciuffo, R.; Colineau, E.; Tuna, F.; Magnani, N.; de Geyer, A.; Pécaut, J.; Mazzanti, M. A Uranium-Based $\mathrm{UO}_{2}{ }^{+}-\mathrm{Mn}^{2+}$ Single-Chain Magnet Assembled trough Cation-Cation Interactions. Angew. Chem. Int. Ed. 2014, 53, 819-823. [CrossRef] [PubMed]

17. Arnold, P.L.; Hollis, E.; Nichol, G.S.; Love, J.B.; Griveau, J.-C.; Caciuffo, R.; Magnani, N.; Maron, L.; Castro, L.; Yahia, A.; et al. Oxo-Functionalization and Reduction of the Uranyl Ion through Lanthanide-Element Bond Homolysis: Synthetic, Structural, and Bonding Analysis of a Series of Singly Reduced Uranyl-Rare Earth $5 \mathrm{f}^{1}-4 \mathrm{f}^{\mathrm{n}}$ Complexes. J. Am. Chem. Soc. 2013, 135, 3841-3854. [CrossRef] [PubMed]

18. Magnani, N. Spectroscopic and magnetic investigations of actinide-based nanomagnets. Int. J. Quantum Chem. 2014, 114, 755-759. [CrossRef]

19. Meihaus, K.R.; Long, J.R. Actinide-based single-molecule magnets. Dalton Trans. 2015, 44, $2517-2528$. [CrossRef] [PubMed]

20. Liddle, S.T.; van Slageren, J. Actinide single-molecule magnets. In Lanthanides and Actinides in Molecular Magnetism, 1st ed.; Layfield, R.A., Murugesu, M., Eds.; Wiley-VCH: Weinheim, Germany, 2015; pp. 315-339. ISBN 9783527335268.

21. Magnani, N.; Colineau, E.; Eloirdi, R.; Griveau, J.-C.; Caciuffo, R.; Cornet, S.M.; May, I.; Sharrad, C.A.; Collison, D.; Winpenny, R.E.P. Superexchange coupling and slow magnetic relaxation in a transuranium polymetallic complex. Phys. Rev. Lett. 2010, 104, 197202. [CrossRef] [PubMed] 
22. Magnani, N.; Apostolidis, C.; Morgenstern, A.; Colineau, E.; Griveau, J.-C.; Bolvin, H.; Walter, O.; Caciuffo, R. Magnetic memory effect in a transuranic mononuclear complex. Angew. Chem. Int. Ed. 2011, 50, 1696-1698. [CrossRef] [PubMed]

23. Magnani, N.; Colineau, E.; Griveau, J.-C.; Apostolidis, C.; Walter, O.; Caciuffo, R. A plutonium-based single-molecule magnet. Chem. Commun. 2014, 50, 8171-8173. [CrossRef] [PubMed]

24. Cornet, S.M.; Häller, L.J.L.; Sarsfield, M.J.; Collison, D.; Helliwell, M.; May, I.; Kaltsoyannis, N. Neptunium(VI) chain and neptunium(VI/V) mixed valence cluster complexes. Chem. Commun. 2009, 917-919. [CrossRef] [PubMed]

25. Streitwieser, A., Jr.; Müller-Westerhoff, U. Bis(cyclooctatetraenyl)uranium (uranocene). A new class of sandwich complexes that utilize atomic f orbitals. J. Am. Chem. Soc. 1968, 90, 7364. [CrossRef]

26. Karraker, D.G.; Stone, J.A.; Jones, E.R., Jr.; Edelstein, N. Bis(cyclooctatetraenyl)neptunium(IV) and bis(cyclooctatetraenyl)plutonium(IV). J. Am. Chem. Soc. 1970, 92, 4841-4845. [CrossRef]

27. Kerridge, A. f-Orbital covalency in the actinocenes $(\mathrm{An}=\mathrm{Th}-\mathrm{Cm})$ : Multiconfigurational studies and topological analysis. RSC Adv. 2014, 4, 12078-12086. [CrossRef]

28. Rinehart, J.D.; Long, J.R. Slow magnetic relaxation in homoleptic trispyrazolylborate complexes of neodymium(III) and uranium(III). Dalton Trans. 2012, 41, 13572-13574. [CrossRef] [PubMed]

29. Apostolidis, C.; Morgenstern, A.; Rebizant, J.; Kanellakopulos, B.; Walter, O.; Powietzka, B.; Karbowiak, M.; Reddmann, H.; Amberger, H.-D. Electronic Structures of Highly Symmetrical Compounds of f Elements 44 [1]. First Parametric Analysis of the Absorption Spectrum of a Molecular Compound of Tervalent Uranium: Tris[hydrotris(1-pyrazolyl)borato]uranium(III). Z. Anorg. Allg. Chem. 2010, 636, 201-208. [CrossRef]

30. Rinehart, J.D.; Long, J.R. Exploiting single-ion anisotropy in the design of f-element single-molecule magnets. Chem. Sci. 2011, 2, 2078-2085. [CrossRef]

31. Rau, J.G.; Gingras, M.J.P. Magnitude of quantum effects in classical spin ices. Phys. Rev. B 2015, $92,144417$. [CrossRef]

32. Ungur, L.; Chibotaru, L.F. Strategies toward High-Temperature Lanthanide-Based Single-Molecule Magnets. Inorg. Chem. 2016, 55, 10043-10056. [CrossRef] [PubMed]

33. Moro, F.; Mills, D.P.; Liddle, S.T.; van Slageren, J. The Inherent Single-Molecule Magnet Character of Trivalent Uranium. Angew. Chem. Int. Ed. 2013, 52, 3430-3433. [CrossRef] [PubMed]

34. Dutkiewicz, M.S.; Apostolidis, C.; Walter, O.; Arnold, P.L. Reduction chemistry of neptunium cyclopentadienide complexes: From structure to understanding. Chem. Sci. 2017, 8, 2553-2561. [CrossRef] [PubMed]

35. Al-Kazzaz, Z.M.S.; Bagnall, K.W.; Brown, D.; Whittaker, B. Octathiocyanato- and octaselenocyanatocomplexes of the tetravalent actinide elements. J. Chem. Soc. Dalton Trans. 1972, 2273-2277. [CrossRef]

36. Arnold, P.L.; Dutkiewicz, M.S.; Zegke, M.; Walter, O.; Apostolidis, C.; Hollis, E.; Pécharman, A.-F.; Magnani, N.; Griveau, J.-C.; Colineau, E.; et al. Subtle Interactions and Electron Transfer between UIII, $\mathrm{Np}^{\mathrm{III}}$, or Pu ${ }^{\mathrm{III}}$ and Uranyl Mediated by the Oxo Group. Angew. Chem. Int. Ed. 2016, 55, 12797-12801. [CrossRef] [PubMed]

37. Dutkiewicz, M.S.; Farnaby, J.H.; Apostolidis, C.; Colineau, E.; Walter, O.; Magnani, N.; Gardiner, M.G.; Love, J.B.; Kaltsoyannis, N.; Caciuffo, R.; et al. Organometallic neptunium(III) complexes. Nat. Chem. 2016, 8, 797-802. [CrossRef] [PubMed]

38. Copping, R.; Mougel, V.; Den Auwer, C.; Berthon, C.; Moisy, P.; Mazzanti, M. A Tetrameric neptunyl(V) cluster supported by a Schiff base ligand. Dalton Trans. 2012, 41, 10900-10902. [CrossRef] [PubMed]

39. Carretta, S.; Amoretti, G.; Santini, P.; Mougel, V.; Mazzanti, M.; Gambarelli, S.; Colineau, E.; Caciuffo, R. Magnetic properties and chiral states of a trimetallic uranium complex. J. Phys. Condens. Matter 2013, 25, 486001. [CrossRef] [PubMed]

40. Mougel, V.; Horeglad, P.; Nocton, G.; Pécaut, J.; Mazzanti, M. Cation-Cation Complexes of Pentavalent Uranyl: From Disproportionation Intermediates to Stable Clusters. Chem. Eur. J. 2010, 16, 14365-14377. [CrossRef] [PubMed]

41. Gaunt, A.J.; Reilly, S.D.; Hayton, T.W.; Scott, B.L.; Neu, M.P. An entry route into non-aqueous plutonyl coordination chemistry. Chem. Commun. 2007, 1659-1661. [CrossRef] [PubMed]

42. Sigmon, G.E.; Ling, J.; Unruh, D.K.; Moore-Shay, L.; Ward, M.; Weaver, B.; Burns, P.C. Uranyl-Peroxide Interactions Favor Nanocluster Self-Assembly. J. Am. Chem. Soc. 2009, 131, 16648-16649. [CrossRef] [PubMed] 
43. Hu, H.-S.; Kaltsoyannis, N. High Spin Ground States in Matryoshka Actinide Nanoclusters: A Computational Study. Chem. Eur. J. 2018, 24, 347-350. [CrossRef] [PubMed]

44. Baldoví, J.J.; Cardona-Serra, S.; Clemente-Juan, J.M.; Coronado, E.; Gaita-Ariño, A. Modeling the properties of uranium-based single ion magnets. Chem. Sci. 2013, 4, 938-946. [CrossRef]

45. Karbowiak, M.; Rudowicz, C. Properties of uranium- and lanthanide-based single-ion magnets modelled by the complete and restricted Hamiltonian approach. Polyhedron 2015, 93, 91-98. [CrossRef]

46. Spivak, M.; Vogiatzis, K.D.; Cramer, C.J.; de Graaf, C.; Gagliardi, L. Quantum Chemical Characterization of Single Molecule Magnets Based on Uranium. J. Phys. Chem. A 2017, 121, 1726-1733. [CrossRef] [PubMed] 